\title{
EXPANSION OF PADDY FARMING IN THE NORTHEAST SEMI-ARID REGION OF CHINA AND ITS IMPACT ON THE LOCAL ENVIRONMENT: \\ CASE STUDIES OF BAICHENG AND DA'AN CITIES, JILIN PROVINCE
}

\author{
Jian Ma
}

\begin{abstract}
China is the most populous country in the world, and ensuring food security for a huge and growing population is the largest issue for the Chinese government. In northern China, especially in arid and semi-arid regions, poor natural enviornment, signified by a high degree of soil salinization, a large number of saline and alkaline land not only hinders the increase of food production but also the promotion of farmers' income. This has impeded regional sustainable development. In order to ameliorate the saline-alkali land, improve the ecological environment, increase rice output and promote farmers' income, China has carried out projects of saline-alkali land amelioration by planting paddy in the northeast semi-arid region since 1980s. Results show that rice cultivation is a very effective way for ameliorating the saline-alkali land, and it can increase the rice while promoting income of farmers. This paper analyzes the cost and benefits of growing rice and examines the impact of paddy farming on the local environment.
\end{abstract}

Keywords: China, Semi-Arid Region, Saline-Alkaline land, Paddy Farming, Environment

\section{Introduction}

China is challenged with continuous population growth coupled with declining availability of agricultural land per capita and increasing food demand. ${ }^{1}$ So it is an arduous task to support over $22 \%$ of the world's population on less than $7 \%$ of world's arable land. ${ }^{2}$ Therefore, China has always put the issue of food security high on its agenda. During the past several decades, China has successfully provided adequate food for its people. ${ }^{3}$

Rice is the most important crop in China and is staple food for $65 \%$ of Chinese. Nowadays more than one hundred million farmers are cultivating rice. Rice production covers $40 \%$ of the total crop production in China and about $30 \%$ of the total production

1 W.C. Lu, "Effects of Agricultural Market Policy on Crop Production in China", Food Policy, Vol. 27, 2002, pp 561-573.

2 Wenhua Li, "Integrated Faming Systems-An Important Approach Toward Sustainable Agriculture in China", Technology Innovation and Sustainable Agriculture, Session 6, OCETS 2000, pp.6-12.

3 Jing Zhu, "Public Investment and China's Long-Term Food Security Under WTO", Food Policy, Vol. 29, 2004, pp 99-111. 
in the world. So securing stable development of rice industry is not only very important to supply adequate food for urbanites, but also to create job opportunities for farmers and increase the total rice production and for preferential trading globally.

However, China's rural and agricultural development is confronted with a series of problems. These include population pressures and land scarcities, shortages of water resources, shortages of energy, pollution threats and an undeveloped rural economy. ${ }^{4}$ Land scarcity is the main problem in the arid and semi-arid region of north China due to the soil salinization and alkalinization, which is threatening agricultural sustainable development.

Songnen plain located in the northeast of China, belongs to the semi-arid and mid-temperate zone. It is one of the three biggest saline and alkaline areas in the world. Areas of salt affected soils reaches 3.5 million hectares currently in the Songnen plain. Annual rising rate of salinization is as high as $1-1.4 \%$ and about $45 \%$ of salt affected land in the area has been degraded into abandoned severe saline land. ${ }^{5}$

The Baicheng region is located in the Songnen Plain, west of Jilin province, China. In three cities - Baicheng, Taonan and Da'an and two counties - Zhenlai and Tongyu, soil salinization and alkalinization restricts agriculture production severely. However, in recent years, cultivating rice irrigated by using groundwater has been a successful method for amelioration of sodic saline soils in western Songnen Plain. ${ }^{6}$ Therefore, amelioration of saline and alkaline soil can be overcome by growing rice in arid and semi-arid lands.

Previous research has shown ameliorating result of saline and alkaline soils by growing rice in the Baicheng region but few of these research illustrate economic profits of rice production and farmers' income. Therefore, this paper has used data collected from field survey to examine rice production in Baicheng and Da'an and analyze the economical profit of rice and farmers' income through paddy farming. The paper equally explores the impact on eco friendly-environment as a result from development of paddy farming in semi-arid lands.

\section{Methodology}

Data was collected from the 2005 Baicheng Statistical Yearbook and other various issues on Report on Cost and Revenue of Agricultural Products in China and three field surveys were conducted in September 2005, April and August 2006 in Baicheng and Da' an city. Tabular and graphical analyses were carried out to show the changes in rice cultivation areas and total production. In addition, income and profit from rice production along with groundwater utilization were analyzed.

4 Wenhua Li, “Integrated Faming Systems-An Important Approach Toward Sustainable Agriculture in China", Technology Innovation and Sustainable Agriculture, Session 6, OCETS2000, pp.6-12

5 Jingsong Yang, "Recent Evolution of Soil Salinization in China and its Driving Processes",18th World Congress of Soil Science, July 9-15, 2006, Philadelphia, Pennsylvania, USA.

6 Qusheng Li, "Transportation of Water and Salt in Paddy Soils of Sodic Saline Region", Ecology and Environment, Vol. 14 No. 3, 2005, pp 1-3. (In Chinese) 
Map of China and Jilin Province Highlighting Survey Areas
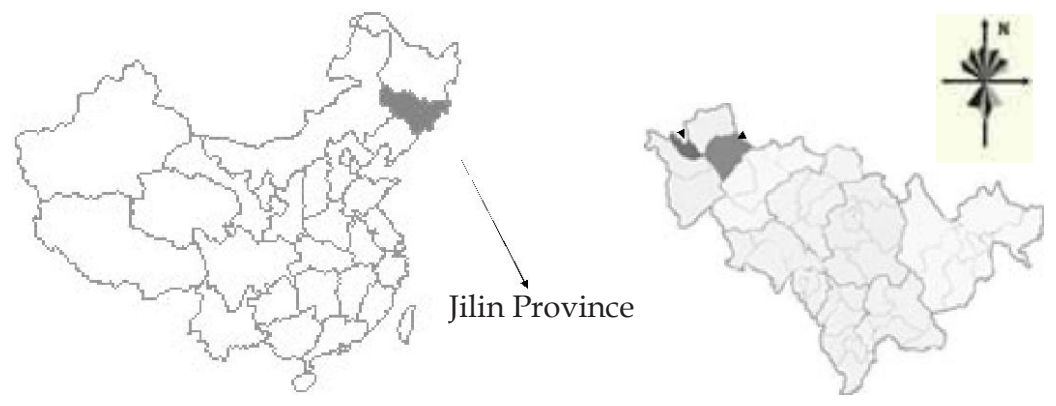

\section{Paddy farming development in Baicheng region}

Baicheng region is a semi-arid region in western Jilin Province (see Map). The average rainfall in Baicheng region is $317.9 \mathrm{~mm}$. However, with global climate changes, the draught in Baicheng city has become more serious. In order to ameliorate the abundant saline and alkaline soil, paddy farming was developed in Baicheng city in 1985 . Within the total rice cultivation area increased from 1 to 20,715 hectares and the total production has been increased from 1 to 144,039 tons by 2004 (see Figure 1).

Figure 1: Changes in Rice Production and Areas in Baicheng City

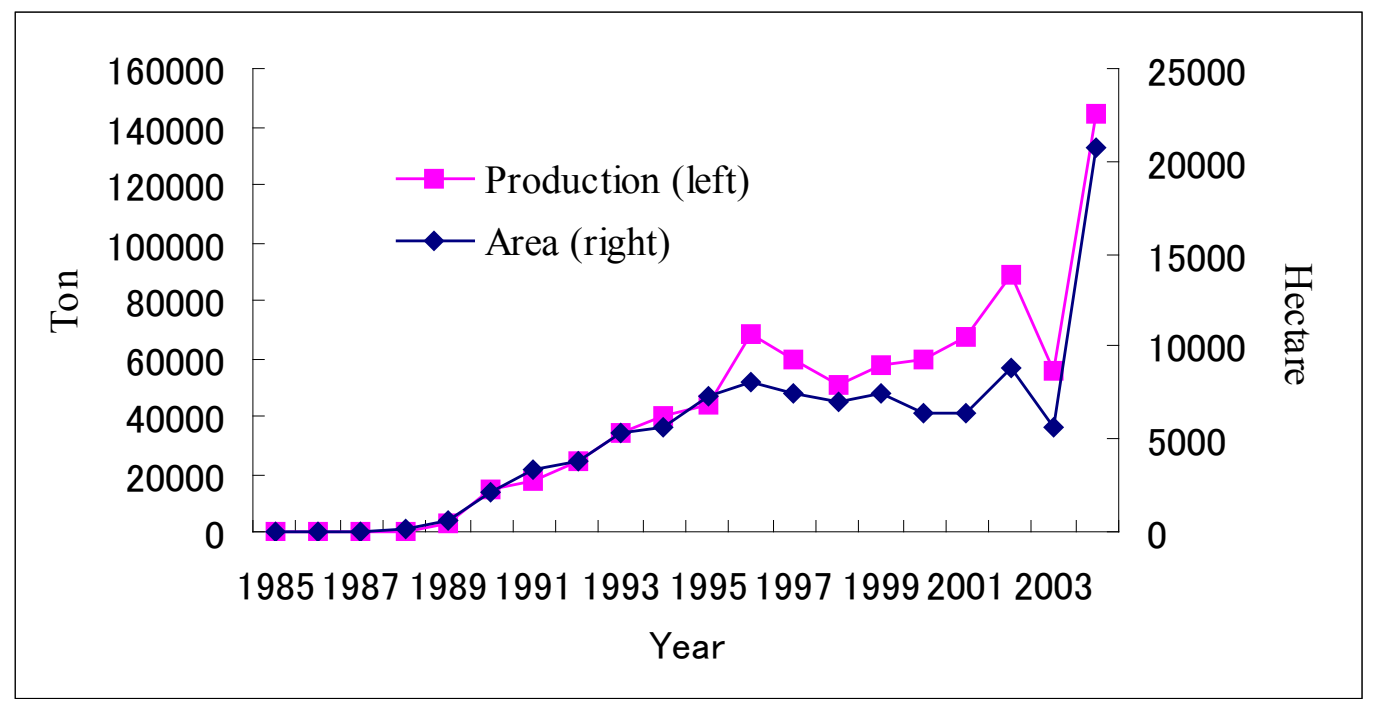

Sources: 2005 Baicheng Statistical Yearbook, Report on Cost and Revenue of Agricultural Products in China and field surveys

\section{The Amelioration of Saline and Alkali Lands by Growing Paddy Rice}

In China, saline-alkali lands can be found throughout arid and semi-arid areas. The saline-alkali lands were formed by the comprehensive influence of an unique climate, hydrology and other natural conditions. In ancient China, there is evidence of 
amelioration of saline and alkaline land by cultivating paddy field farming. ${ }^{7}$ Baicheng and Da'an cities were chosen as the survey areas for several reasons. Firstly, both Baicheng and Da' an cities use groundwater for paddy farming. The groundwater in Baicheng city is easy to use and rice-cultivating areas has increased rapidly in recent years due to the high price of rice. Secondly, soil salinization and alkalinization is more serious in Da'an city than any other place in the Baicheng region and the usage of amelioration equipment for growing rice is more common. So local farmers in Da' an city have more experiences of amelioration of saline and alkaline soils.

\section{Paddy Farming in Baicheng City}

Paddy farming in Baicheng city began in 1985, mainly for ameliorating saline and alkaline soils as well as for increasing rice production. After more than 20 years, Baicheng city has become more than self-sufficient in rice production and has the ability to export rice to other regions. Irrigation in Baicheng city is based on groundwater without proper drainage system. Therefore, the salt and alkali materials are not fully drained by the water. In fact, saline and alkaline soils in Baicheng city are not ameliorated due to incomplete drainage facilities.

\section{Paddy Farming in Da'an City}

Soil salinization and alkalinization in Da'an city is more serious than any other place in the Baicheng region. Soil salinization and alkalinization cover $62.2 \%$ of the total land areas in Da'an city. Paddy farming began in 1983 in order to ameliorate the saline and alkaline soils. ${ }^{8}$ The irrigation water for paddy farming is from groundwater and unlike Baicheng city, there are drainage canals in Da'an city. Therefore, salt and alkali are drained by water and hence saline and alkaline soils in the city are ameliorated by sufficient drainage facilities.

Table 1 Increase of Rice Cultivated Areas and Total Production in Two Cities

\begin{tabular}{|l|l|l|l|l|}
\hline \multicolumn{3}{|l|}{ Cultivated areas (ha) } & \multicolumn{3}{l|}{ Total rough rice production (ton) } \\
\hline & Baicheng & Da'an & Baicheng & Da'an \\
\hline 1987 & 12 & 600 & 58 & 459 \\
\hline 2004 & 20,715 & 3,020 & 144,039 & 14,452 \\
\hline CAGR $(\%)$ & 55.03 & 9.97 & 58.38 & 22.50 \\
\hline
\end{tabular}

Source: Baicheng Statistical Yearbook $(1988,2005)$

Note: CAGR (Compound Annual Growth Rate) $=(\text { A, P2004/ A, P1987) })^{1 / 17-1}$

7 Zhanyi Gao, Youyi Zhang \& Xingye Qu. “The Prevention and Amelioration of Saline and Alkali soil in China", available from http://www.lanl.gov/Chinawater/documents/Gaozhanyi. pdf , accessed 10 August 2015.

8 Bin Li, Zhichun Wang, Zhengwei Liang, and Chunming Chi, "Quality of Groundwater in Sodic soil Areas in Da' an City and Soil Salinization Risk of Using the Water for Irrigation", Vol. 22 No. 4, 2006, pp 20-24. (In Chinese) 
Table 1 shows the increase of rice cultivated areas and total estimate of rice production in both Baicheng city and Da'an city. Rice cultivated areas increased from 12 ha in 1987 to 20,715 ha in 2004, and the total production increased from 58 tons in 1987 to 144,039 tons in 2004 in Baicheng city. In comparison, rice cultivated areas increased from 600 ha in 1987 to 3,020 ha in 2004, and the total production increased from 459 tons to 14,452 tons in 2004 in Da' an city. In Baicheng city, due to the easier use of groundwater and better land condition (compared to Da'an city), we used the Compound Annual Growth Rate (CAGR) to confirm the scale of paddy farming in Baicheng city is faster than Da'an city.

\section{Income and Cost Analysis for Rice Cultivating Farmers in Two Cities}

Two field surveys were carried out in Baicheng region in 2006. One was conducted in Baicheng city in April and there were visits to two rice-cultivating farmers. The other was done in Da' an city in August and visits to two rice-cultivating farmers were deemed appropriate to collect data for the year 2005. Table 2 shows the cost and net profit analysis of four farmers both in Baicheng and Da'an cities.

Table 2 Cost and Net Profit Analysis of Four Rice-cultivating Farmers in Baicheng and Da'an Cities

\begin{tabular}{|c|c|c|c|c|c|}
\hline & & & & & \\
\hline & & F1 & $\mathrm{F} 2$ & F3 & $\mathrm{F} 4$ \\
\hline (1) & Rice cultivating area (ha) & 6 & 10 & 1 & 2 \\
\hline (2) & Total rough rice production (ton) & 57 & 85 & 7 & 16 \\
\hline (3) & Per-hectare production: (2)/(1) & 9.5 & 8.5 & 7.0 & 8.0 \\
\hline (4) & Total cost (Yuan) & 85,720 & 138,800 & 5,500 & 10,400 \\
\hline (5) & Total income & 106,020 & 156,400 & 12,880 & 29,440 \\
\hline (6) & Total net profit: (5)-(4) & 20,300 & 17,600 & 7,380 & 19,040 \\
\hline (7) & Per-ton income: (5)/(2) & 1,860 & 1,840 & 1,840 & 1,840 \\
\hline (8) & Per-ton cost: (4)/ (2) & 1,504 & 1,633 & 786 & 650 \\
\hline & Fertilizer & 728 & 789 & 286 & 312 \\
\hline & Agrochemicals & 105 & 118 & 57 & 63 \\
\hline & Plastic house & 44 & 41 & - & - \\
\hline & Fuel & 137 & 149 & 71 & 50 \\
\hline & Land rent & 105 & 118 & 100 & 69 \\
\hline & Threshing & 32 & 35 & 143 & 31 \\
\hline & Hired labor & 353 & 383 & 129 & 125 \\
\hline (9) & Per-ton net profit: (7)-(8) & 356 & 207 & 1,054 & 1,190 \\
\hline (10) & Net profit rate $(\%):(6) /(5)$ & 19.2 & 11.3 & 57.3 & 64.7 \\
\hline
\end{tabular}

Source: Field survey conducted in 2006

Baicheng city has larage area but with lesser population and the soil condition is better than found in Da'an city. Table 2 shows that the rice-cultivating areas of two farmers in Baicheng city are bigger than the two farmers in Da' an city. With a bigger rice cultivating area and more rice production, total rural income in Baicheng city is 
much higher. However, per-ton cost of rice in Baicheng city is much more than the perton cost in $\mathrm{Da}^{\prime}$ an city, the higher cost has led to lower net profit rates in Baicheng city.

The cost components of rice production consist of fertilizers, agrochemicals, plastic house, fuel, land rent, threshing and hired labour cost. Fertilizers, agrochemicals and hired labour costs in Baicheng city are higher than Da'an city, especially the cost of fertilizers, which is double the price than in Da'an city. Therefore, it can be inferred that overuse of fertilizers and chemicals during rice production in Baicheng city is higher than Da' an city. As such, this is the main reason for the lower per-ton net profits of rice production in Baicheng city.

Table 3 Comparison of Net Profit of per Hectare among Rice, Corn and Soybean

\begin{tabular}{llc|c} 
& & Baicheng & (Unit: Yuan) \\
& & 2,369 & Daan \\
\hline \multirow{2}{*}{ Jilin Province } & Rice (1) & & 8,807 \\
\hline \multirow{2}{*}{ Gap } & Corn (2) & & 961 \\
& Soybean (3) & 1,408 & 2,105 \\
\hline
\end{tabular}

Note: Data for Baicheng and Daan cities were calculated using Table 2. Data for Jilin province is from “Report on Cost and Revenue of Agricultural Products in China" 2005, pp 221 and 238.

Although the per-ton net profits of rice production in Baicheng city is lesser than in Da'an city, when compared to corn and soybean production, main products besides rice in Jilin province, rice is an economically viable crop that has the potential to increase farmers' income in the future. Table 3 shows the comparison of net profits of per-hectare among rice, corn and soybean in Jilin province. It shows that the per-ha net profits of rice production is higher than corn or soybean. Therefore, paddy farming in Baicheng and Da' an city is helpful to promote farmers' income, especially in Da'an city. This is a significant factor in solving rural poverty and stabilizing China's development of rural areas.

\section{Impact on Eco-environment as a Result of Paddy Farming in Two Cities}

Paddy farming needs adequate water supply in arid or semi-arid lands. Water is the scarcest resource in these lands not only for everyday living but also for agricultural production. Baicheng region is rich in groundwater that provides relatively enough water for rice production. From late 1980s, as paddy farming developed in Baicheng and Da'an city, the increasing area of total rice production increased groundwater utilization. Hence excessive use of groundwater has become a major problem. 
Table 4 Increase of Wells and Groundwater Utilization in Two Cities

\begin{tabular}{lccc|ccc} 
& \multicolumn{3}{c}{} & \multicolumn{3}{c}{ (Unit of GU: Million m $\left.{ }^{3}\right)$} \\
& Wa' an city \\
\cline { 2 - 7 } & Well & GU & Ratio (\%) & Well & GU & Ratio (\%) \\
\hline 1998 & 23,931 & 295 & 82.4 & 3,654 & 115 & 27.4 \\
2004 & 26,856 & 618 & 172.6 & 4,789 & 224 & 53.3 \\
Resource & - & 358 & 100 & - & 420 & 100 \\
CAGR (\%) & 1.94 & 13.12 & - & 4.64 & 11.75 & -
\end{tabular}

Source: Baicheng Statistical Yearbook, various issues, Zhang Hongxia "Suggestion for river water use in Daan city". Jilin Water, China, 2004-2009, pp 38.

Note: CAGR (Compound Annual Growth Rate) $=\left(W\right.$, GU2004/ W, GU1998) ${ }^{1 / 6-1}$ GU is the short write for the groundwater utilization Resource is means the groundwater quantity could be easily used Ratio is means the GU/Resource*100

Table 4 shows the number of wells and groundwater utilization increase, especially in Baicheng city, due to the development of large rice cultivating areas. The groundwater utilization increased from 295 million $\mathrm{m}^{3}$ in 1998 to 618 million $\mathrm{m}^{3}$ in 2004 and the ratio increased from $82.40 \%$ in 1998 to $172.63 \%$ in 2004 . In Da' an city the groundwater utilization increased from 115 million $\mathrm{m}^{3}$ in 1998 to 224 million $\mathrm{m}^{3}$ in 2004. It is clear that overuse of groundwater is more serious in Baicheng city than Da' an city. Therefore, groundwater resource will continue to be a major factor-restricting paddy farming in Baicheng region. Thus, such water problem must be resolved not only for sustainable paddy farming but also for improving people's daily lives.

Fortunately, the local government is alert about the groundwater utilization crisis. Now, there are two water diversion programs; one is diverting water from Nenjiang River (which belongs to the Heilongjiang province) to Baicheng city and the other is diverting water from Nenjiang River to Da' an city. If these two programs are successful, it is expected to overcome the groundwater utilizatio crisis and supply adequate water for paddy farming and for human consumption.

Table 5 Summarization of Paddy Farming in Baicheng and Da'an city

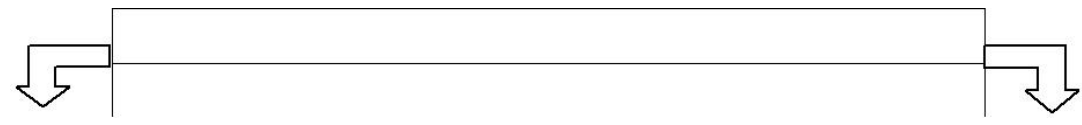

Soil salinization and alkalinization

Amelioration by growing paddy rice

\begin{tabular}{|c|c|}
\hline Baicheng city & Da'an city \\
\hline Irrigation by groundwater & Irrigation by groundwater \\
\hline No drainage system & Drainage by canal \\
\hline Salt and alkali are not drained by water & $\begin{array}{c}\text { Salt and alkali are drained into other place by } \\
\text { water }\end{array}$ \\
\hline $\begin{array}{c}\text { Saline and alkaline soils are not completely } \\
\text { ameliorated by growing paddy rice }\end{array}$ & $\begin{array}{c}\text { Saline and alkaline soils are ameliorated by } \\
\text { growing paddy rice }\end{array}$ \\
\hline Secondary soil salinization & Drained salt and alkali pollute other places \\
\hline
\end{tabular}

Source: Author's observations 
Table 5 shows that in Baicheng city, the saline and alkaline soils are not completely ameliorated due to incomplete drainage facilities. As a result, this easily causes secondary soil salinization. In Da'an city, the saline and alkaline soils are ameliorated by complete irrigation and drainage system. But the salt and alkali gets distributed to other place; a marshland named Xiao Xinmi, in the middle of Da'an city. As salt and alkali get concentrated, soil salinization and alkalinization has increased in the Xiao Xinmi marshland. As a result, while paddy farming successfully ameliorated the saline and alkaline soils in Da' an city, at the same time the drained salt and alkali pollutes nearby areas.

\section{Conclusions}

Paddy farming in Baicheng and Da'an city has contributed to the increase of farmers' income. But the increase in income is at the cost of excessive use of scarce water resources; especially groundwater resource. Therefore, it can be concluded that rice is an economically viable crop, which has the potential to increase farmers' income in Baicheng and Da'an city. However, inefficient water management is a major factor restricting sustainable paddy farming in the Baicheng region. Therefore, the following conclusions can be made: rice production has good prospects in terms of profitability to increase farmers' income in Baicheng and Da'an cities. Paddy development has led to overuse of groundwater in Baicheng city in recent years, which in the end has become a major factor in restricting paddy farming in the Baicheng region. Saline and alkaline soils are not ameliorated in Baicheng city by growing paddy rice due to the lack of drainage system. In comparison saline and alkaline soils are ameliorated in Da'an city by growing paddy rice due to efficient use of drainage system.

Therefore, in order to be sustainable, Baicheng and Da' an must be improve the farm management on two aspects: Firstly, by developing proper facilities for paddy farming and water utilization. Secondly, perfecting the irrigation and drainage system in these two cities. In so doing, it is possible that saline and alkaline soils can be ameliorated better than before and paddy farming can be part of sustainable development in the future in China. 